\title{
Support for genetic diversity project
}

Sir - I am writing in response to a recent article on a report from the US National Research Council, Evaluating Human Genetic Diversity (Nature 389, 774; 1997). I chaired the committee that wrote the report.

The article was correct in stating that the committee does not think that the "consensus document" drafted in 1993 and which has been construed as the Human Genetic Diversity Project sets forth a clearly articulated, sharply defined proposal that the committee could evaluate. However, this does not constitute disapproval of the concept behind the proposal; indeed, the committee strongly endorsed the scientific merits of a global study of human genetic variation. A global study performed in a way that would not reveal the identities of the DNA donors or compromise their rights could be of tremendous value for researchers who study human origins or anthropology. The committee believes that such a survey, if performed to protect the rights of individual donors, does merit federal funding.

And your article is in error when it asserts that the committee recommends that federal funding agencies "should confine support of human genome diversity work to projects inside the United States". Our recommendation reads: "These agencies should focus their financial support, at least initially, on projects originating in the United States and expand their support to the international scene only after the US activities are successfully launched." The word 'originating' is not synonymous with 'inside' nor did we expect it to be so construed. Our intention was to ensure that research, wherever it might be pursued geographically, would have to meet all of the ethical and legal restrictions at present placed on human genetic research funded by federal agencies in the United
States. We believed this aim could be achieved only through restricting research applications to those that sought US federal monies.

William J. Schull

Committee on Human Genome Diversity,

National Research Council,

2101 Constitution Avenue,

Washington, DC 20418, USA

Sir - The News item by Colin Macilwain (Nature 389, 774; 1997) covering the recent prepublication report of the US National Research Council (NRC) about research on human genetic variation as proposed in the Human Genome Diversity Project (HGDP), cites only a few of the findings and recommendations in a comprehensive, informative and, by our reading, favourable evaluation prepared by the expert NRC reviewing committee. The News item reflects your journal's apparent continuing bias against this scientifically acclaimed project.

The task of the NRC committee, formed at the request of the US National Science Foundation (NSF) and National Institutes of Health (NIH), was to assess the scientific value, technical aspects and organizational requirements of a systematic worldwide survey of human genetic variability, as well as the ethical, legal and social issues raised by the project.

The report, some 81 typewritten pages, contains, in addition to an executive summary and an introduction and background, five chapters dealing with, respectively, scientific and medical value of the proposed research, population sampling issues, sample collection and data management, ethical and human rights issues with respect to the project, and organization and funding support aspects.

The reviewing committee has concluded that "a global assessment of the extent of human genetic variability has substantial merit and warrants support" and noted that the "most well-developed and widely recognized proposal for conducting such a survey is known as the... HGDP".

Contrast the committee evaluation with your headline, "Diversity project 'does not merit federal funding"', echoed in the first paragraph of the News item, a phrase that is not found in the NRC report.

The NRC committee indeed suggests that the NSF and NIH should finance projects originating in the United States at least initially and "expand their support to the international scene only after the US activities are successfully launched". These recommendations are understandably directed at US funding agencies and cannot and are not intended to refer to existing and future studies funded by agencies in other parts of the world.

Macilwain mixes roughly equal quantities of facts, in and out of date, with interpretations which do not reflect the NRC report in fashioning the News article. Projects that call themselves HGDP or reflect similar aims have started in half of the world.

\section{Luca Cavalli-Sforza}

Department of Genetics,

Stanford University School of Medicine,

Stanford, California 94305, USA

e-mail:cavalli@lotka.stanford.edu

\section{Walter Bodmer}

(Former President, Human Genome Organisation) Hertford College, Oxford OX13BW, UK

e-mail:walter.bodmer@hertford.ox.ac.uk

\section{Jean Dausset}

Fondation Jean Dausset,

Centre d'Etude du Polymorphisme Humain,

27 rue Juliette Dodu, 75010 Paris, France

e-mail:Jean.Dausset@cephb.fr

The headline of the story was misleading. We reject the allegations of editorial bias. Editor, Nature.

\section{Patients and patents}

Sir - Thomas et al. present data showing that the largest single category of patents published in 1995 that included claims for human DNA sequences was in the area of genetic diagnostics, and that 40 per cent of the patents they identified originated from US public-sector institutions (Nature 388, 709; 1997).

We take exception to their conclusion that public-sector researchers realize that "patenting optimizes the chances of patients receiving benefits from their scientific research".

The more likely explanation for this observation is that researchers and their institutions realize that they can cash in on these discoveries from windfall profits from research supported in part by the taxpayers.

Rather than optimizing patient benefit, these patents threaten to curtail research, raise the price and lower the availability of testing, threaten patient privacy because of potential litigation and insert a troubling and unseemly profit motive into the dissemination and use of genetic testing services.

Thomas et al. also state that industry will not invest in treatments without adequate patent protection, but there is no reason to believe that patenting of basic information about the human genome - particularly about naturally occurring human genomic sequences and the association of mutation with disease - is necessary to promote downstream therapeutic development. To our minds, the risks of these patents far outweigh the potential benefits, and they should be prohibited.

Mildred K. Cho

Jon F. Merz

University of Pennsylvania,

Center for Bioethics,

Suite 320, 3401 Market Street,

Philadelphia,

Pennsylvania 19104-3308, USA 